\title{
Type I interferon receptor in peripheral blood mononuclear cells may predict response to intra-arterial 5-fluorouracil + interferon therapy for advanced hepatocellular carcinoma
}

\author{
This article was published in the following Dove Press journal: \\ Hepatic Medicine: Evidence and Research \\ 21 April 2011 \\ Number of times this article has been viewed
}

\author{
Yasuyuki Tomiyama' \\ Naoko Yoshioka' \\ Yoshiaki Yanai ${ }^{2,3}$ \\ Tomoya Kawase' \\ Sohji Nishina' \\ Yuichi Hara' \\ Koji Yoshida' \\ Keiko Korenaga' \\ Masaaki Korenaga' \\ Keisuke Hino' \\ 'Department of Hepatology and \\ Pancreatology, Kawasaki Medical \\ University, Kurashiki, Japan; \\ ${ }^{2}$ Institute of Fujisaki, Hayashibara \\ Biochemical Lab Inc, Okayama, Japan; \\ ${ }^{3}$ Pharmaceutical Marketing Division, \\ Otsuka Pharmaceutical Co Ltd, Tokyo, \\ Japan
}

\begin{abstract}
Background: Type 1 interferon alpha receptor 2 (IFNAR2) in the liver has been reported to be a predictive factor for the response to intra-arterial 5-fluorouracil (5-FU) + systemic interferon (IFN)-alpha combination therapy in patients with advanced hepatocellular carcinoma. We tested whether IFNAR2 expression in peripheral blood mononuclear cells could predict the response to 5 -FU + IFN.
\end{abstract}

Methods: Predictive factors for survival and response to therapy were determined in 30 patients with advanced hepatocellular carcinoma who underwent treatment with 5-FU + IFN. IFNAR2 expression in peripheral blood mononuclear cells was measured in 11 of the 30 patients.

Results: With a mean number of 4.2 courses of combination therapy, one patient ( $3 \%$ ) showed a complete response, eight (27\%) showed partial responses, 13 (43\%) had stable disease, and eight $(27 \%)$ showed progressive disease. The median survival time of responders (complete response/partial response) was 12.7 months and that of nonresponders (stable disease/progressive disease) was 7.5 months. The one-year and two-year cumulative survival rates of responders and nonresponders were $87 / 69 \%$ and $40 / 11 \%$, respectively $(P=0.019)$. Multivariate analysis identified response to therapy $(P=0.037)$ as the sole independent determinant of survival. The expression level of IFNAR2 in peripheral blood mononuclear cells was significantly $(P=0.012)$ higher in responders $(6.5 \pm 2.4)$ than in nonresponders $(2.4 \pm 0.6)$, even though no clinical factors were identified as being associated with the response to the combination therapy.

Conclusion: IFNAR2 expression in peripheral blood mononuclear cells may predict the response to 5-FU + IFN therapy in patients with advanced hepatocellular carcinoma, although these data are preliminary.

Keywords: interferon, 5-fluorouracil, hepatocellular carcinoma, receptor

\section{Introduction}

Hepatocellular carcinoma is the third leading cause of cancer-related death globally, behind lung and stomach cancers. ${ }^{1}$ Its incidence has been increasing in Japan in the last 30 years $^{2}$ and also in the US more recently. ${ }^{3}$ Intensive management of patients at high risk for hepatocellular carcinoma and advances in diagnostic techniques have facilitated the detection of hepatocellular carcinoma in the early stage. ${ }^{4-7}$ Simultaneously, several therapeutic modalities, including hepatic resection, liver transplantation, radiofrequency ablation, percutaneous ethanol injection, and transcatheter arterial chemoembolization have substantially improved the prognosis of patients with hepatocellular carcinoma. ${ }^{8-11}$ Nevertheless, we still sometimes see patients with advanced hepatocellular carcinoma
Correspondence: Keisuke Hino Department of Hepatology and Pancreatology, Kawasaki Medical University, 577 Matsushima, Kurashiki 701-0192, Japan

$\mathrm{Tel}+8186462$ IIII

$\mathrm{Fax}+8186464$ II96

Email khino@med.kawasaki-m.ac.jp 
at their first visit or after repeated treatment due to the frequent recurrence of the disease.

The prognosis of patients with advanced hepatocellular carcinoma, especially if complicated by portal venous invasion, is extremely poor. ${ }^{12,13}$ Recently, sorafenib, an oral multikinase inhibitor of the vascular endothelial growth factor receptor, the platelet-derived growth factor receptor, and Raf, has been shown to prolong median survival time and the time to progression by nearly three months in patients with advanced hepatocellular carcinoma as compared with those given placebo. ${ }^{14}$ However, no complete responses and only a few partial responses $(2 \%)$ were found in the same study. Although sorafenib can be used for the treatment of patients with advanced hepatocellular carcinoma, its clinical effectiveness is still controversial in Japan. According to the consensus-based clinical manual proposed by the Japan Society of Hepatology, ${ }^{15}$ arterial infusion chemotherapy using an implantable drug delivery system is recommended as one of the treatments for advanced hepatocellular carcinoma with portal venous invasion, based on the favorable results of combination therapy with intra-arterial 5-fluorouracil $(5-\mathrm{FU})+$ systemic interferon $(\mathrm{IFN})^{16-19}$ or another combination of low-dose cisplatin +5 -FU. ${ }^{20,21}$ To improve the effects of these combination therapies and to increase the response rates, it is important to find a practical and useful predictor of the response to therapy. Hepatic expression of type I interferon alpha receptor 2 (IFNAR2) has been shown to correlate with the response to $5-\mathrm{FU}+$ IFN in patients with advanced hepatocellular carcinoma and portal venous invasion. ${ }^{17}$ However, liver biopsy is sometimes difficult to perform before combination therapy in patients with advanced hepatocellular carcinoma because of a bleeding tendency with a low count platelet and/or decreased activity of prothrombin. In this pilot study, we tested whether IFNAR2 expression in peripheral blood mononuclear cells could predict the response to $5-\mathrm{FU}+$ IFN in patients with advanced hepatocellular carcinoma.

\section{Materials and methods}

\section{Patients}

A single-arm, open-label study of intra-arterial combination therapy was conducted in patients with advanced hepatocellular carcinoma. Eligibility criteria were as follows: hepatocellular carcinoma with tumor thrombi invading at least one of the major branches of the portal vein (Vp3 or Vp4, according to the criteria of the Liver Cancer Study Group of Japan [LCSGJ]) or multiple intrahepatic metastases in more than three segments, irrespective of the degree of portal venous invasion (Vp1, Vp2, Vp3, or Vp4); tumor staging III or IVA based on the TNM (tumor node metastasis) staging system of the LCSGJ; absence of extrahepatic metastases; Child-Pugh A or B liver function; an Eastern Cooperative Oncology Group (ECOG) performance status of $0-1 ; 22$ leukocyte count $>2000 / \mu \mathrm{L}$; platelet count $>50,000 / \mu \mathrm{L}$; unresectable disease or not suitable for local ablation therapy; and unlikelihood of effectiveness with transcatheter arterial chemoembolization. All patients provided written informed consent for this study, which was approved by the institutional review board of Kawasaki Medical University.

\section{Implantation of intra-arterial catheter}

An indwelling intra-arterial catheter (Piolax W spiral catheter, Piolax Medical Devices Inc, Kanagawa, Japan) was inserted through the femoral artery by the Seldinger method, and its tip was put in the proper hepatic artery or common hepatic artery, embolizing the right gastric and gastroduodenal arteries to avoid efflux of chemotherapeutic agents into the stomach and duodenum. The other end of the catheter was connected to the injection port (Vital-Port, Cook Japan, Tokyo, Japan) subcutaneously implanted in the lower abdomen.

\section{Evaluation of response to therapy}

The response to therapy was assessed with contrast-enhanced computed tomography after each therapeutic cycle. The response was defined according to the Response Evaluation Criteria in Solid Tumors (RECIST) ${ }^{23}$ as: complete response (complete disappearance of all target lesions); partial response (at least a 30\% decrease in the sum of the longest diameter of the target lesions), taking as reference the baseline sum of the longest diameter; progressive disease (at least a $20 \%$ increase in the sum of the longest diameter of target lesions or the appearance of one or more new lesions); or stable disease (neither partial response nor progressive disease criteria). The best response to therapy was defined as the response to therapy when a different response, such as partial response or stable disease, was found in the same patient during multiple treatment cycles. Adverse reactions were assessed using the National Cancer Institute Common Toxicity Criteria (NCI-CTC, version 3.0, [http://ctep.cancer. gov/reporting/ctc.html]).

\section{Treatment protocol}

One cycle of treatment consisted of four weeks in which $5 \times 10^{6} \mathrm{U}(5 \mathrm{MU})$ of IFN-alpha (OIF; Otsuka Pharmaceutical, Tokyo, Japan) was administered intramuscularly 
on days 1,3 , and 5 of each week, resulting in a total dose of 60 MU per cycle. 5-FU (Kyowa Hakko, Tokyo Japan) $500 \mathrm{mg} /$ day was administered into the hepatic artery over five hours using a portable infusion pump on days 1-5 of the first and second weeks ( $5 \mathrm{~g}$ per cycle). The combination therapy was discontinued in patients who did not meet the eligibility criteria and also in those with progressive disease or NCI-CTC Grade 3 adverse reactions, otherwise the treatment was repeated after a $2-4$-week rest period without treatment.

\section{Measurement of IFNAR2 expression in peripheral blood mononuclear cells}

Peripheral blood mononuclear cells were separated from $10 \mathrm{~mL}$ of heparinized blood by density gradient centrifugation using Ficoll-Hypaque (Amersham Pharmacia Biotech, Uppsala, Sweden), washed three times with RPMI 1640 culture medium, and stored at $-80^{\circ} \mathrm{C}$ until use. RNA was extracted from the homogenized peripheral blood mononuclear cells using a High Pure RNA kit (Roche Diagnostics Ltd, Germany), and its integrity was confirmed by spectrophotometry. The IFNAR2 mRNA expression level was quantified using an ABI PRISM 7700 Sequence Detection System (Applied Biosystems, Foster City, CA) and real-time reverse transcription polymerase chain reaction (RT-PCR), as described previously. ${ }^{24}$ Briefly, a RT-PCR assay was performed on a $25 \mu \mathrm{L}$ reaction mixture containing $20 \mathrm{ng}$ of sample cDNA, $100 \mathrm{nM}$ sense primer, $100 \mathrm{nM}$ antisense primer, and $12.5 \mu \mathrm{L}$ of SYBR Green PCR Master Mix (Applied Biosystems). The following specific primers were designed to amplify their respective genes; IFNAR2, sense; 5'-GAAGGTGGTTAAGAACTGTGC-3', antisense; 5'-CCCGCTGAATCCTTCTAGGACGG-3'; $\beta 2$-microglobulin, sense; $5^{\prime}$-ACCCCCACTGAAAAAGAT GA-3', antisense; 5'-ATCTTCAAACCTCCATGATG-3'. The PCR was carried out for 45 cycles at $95^{\circ} \mathrm{C}$ for $15 \mathrm{sec}-$ onds and $60^{\circ} \mathrm{C}$ for one minute. A standard curve for each mRNA expression was generated using five-fold dilutions of a control RNA sample $(25 \times, 5 \times, 1 \times, 0.2 \times$, and $0.04 \times)$. The mRNA expression levels of the target genes (IFNAR2) were presented as a ratio to that of $\beta 2$-microglobulin, and the relative expression levels were calculated.

\section{Statistical analysis}

Quantitative values were expressed as the mean \pm standard deviation. Cumulative survival was calculated using the Kaplan-Meier method, and the differences between the groups were analyzed using the log-rank test. Univariate and multivariate analyses of predictors of survival were assessed by the Cox proportional hazards model. Univariate and multivariate analyses of predictors for the response to therapy were assessed by the logistic regression test. Differences between the two groups were examined for statistical significance using the Mann-Whitney $U$ test. A $P$ value $<0.05$ was considered to be statistically significant. All analyses described above were performed using SPSS software (version 11, SPSS Inc, Chicago, IL).

\section{Results}

\section{Patient profile}

Forty-five patients with advanced hepatocellular carcinoma fulfilled the eligibility criteria for 5-FU + IFN therapy. Among them, 30 patients ( 24 men and six women) with an average age of $64.7 \pm 1.8$ (range 48-84) years provided written informed consent to receive the combination therapy. Patient characteristics at baseline are shown in Table 1. Eight patients were positive for both hepatitis B (HBV) surface antigen and HBV DNA, and 18 for both anti-hepatitis C virus (HCV) and HCV RNA. The remaining four patients were negative for both hepatitis B surface antigen and anti-HCV. Liver disease stage was Child-Pugh A and tumor stage was IV in 23 patients $(76.7 \%)$. The integrated staging scores for the Japan Integrated Staging ${ }^{25}$ and Cancer of the Liver Italian Program $(\mathrm{CLIP})^{13}$ were $\geq 3$ in $23(76.7 \%)$ and 17 patients $(56.7 \%)$, respectively. Twelve patients $(40 \%)$ had portal venous invasion at a major branch (Vp3) or in the main trunk (Vp4).

Table I Patient characteristics

\begin{tabular}{|c|c|}
\hline Number of patients & 30 \\
\hline Age, years, mean \pm SD (range) & $64.7 \pm 1.77(48-84)$ \\
\hline Gender, male/female & $24 / 6$ \\
\hline Etiology (HBV/HCV/NBNC) & $8 / 18 / 4$ \\
\hline Total bilirubin (mean $\pm \mathrm{SD}, \mathrm{mg} / \mathrm{dL}$ ) & $I . I \pm 0.1$ \\
\hline Albumin (mean $\pm \mathrm{SD}, \mathrm{g} / \mathrm{dL})$ & $3.5 \pm 0.08$ \\
\hline Prothrombin time (mean \pm SD, \%) & $77.2 \pm 2.2$ \\
\hline Platelet count (mean $\left.\pm S D, \times 10^{4} / \mu \mathrm{L}\right)$ & $14.7 \pm 1.4$ \\
\hline $\operatorname{AFP}($ mean $\pm S D, n g / m L)$ & $33,715 \pm 13,255$ \\
\hline AFP-L3 (mean \pm SD, \%) & $23.1 \pm 4.6$ \\
\hline $\mathrm{DCP}($ mean $\pm \mathrm{SD}, \mathrm{mAU} / \mathrm{mL})$ & $37,905 \pm 17,417$ \\
\hline Child-Pugh status $(\mathrm{A} / \mathrm{B} / \mathrm{C})$ & $23 / 7 / 0$ \\
\hline TNM staging by LCSGJ (III/IVA) & $7 / 23$ \\
\hline JIS score $(I, 2 / 3,4,5)$ & $7 / 23$ \\
\hline CLIP score $(I, 2 / 3,4,5)$ & $13 / 17$ \\
\hline Portal vein invasion $\left(\mathrm{V}_{\mathrm{p}} \mathrm{I}\right.$ or $\mathrm{V}_{\mathrm{p} 2} / \mathrm{V}_{\mathrm{p}} 3$ or $\left.\mathrm{V}_{\mathrm{p}} 4\right)$ & $18 / 12$ \\
\hline
\end{tabular}

Abbreviations: $\mathrm{HBV}$, hepatitis $B$ virus; $\mathrm{HCV}$, hepatitis $\mathrm{C}$ virus; $\mathrm{NBNC}$, non-HBV non-HCV; AFP, $\alpha$-fetoprotein; DCP, des- $\gamma$-carboxy prothrombin; TNM, tumor node metastasis; LCSG], Liver Cancer Study Group of Japan; JIS, Japan integrated staging; CLIP, Cancer of the Liver Italian Program; SD, standard deviation. 


\section{Response to combination therapy and survival}

Thirty patients with advanced hepatocellular carcinoma completed 5-FU + IFN therapy, with a mean treatment cycle number of 4.2 (range 2-12). The median survival time was 7.5 months, and the one-year and two-year cumulative survival rates were $53 \%$ and $33 \%$, respectively. Of these 30 patients, one $(3 \%)$ had a complete response, eight $(27 \%)$ had a partial response, $13(43 \%)$ had stable disease, and 8 (27\%) had progressive disease, ie, nine (30\%) had objective responses (complete response or partial response). The median survival time of responders (complete response/ partial response) was 12.7 months and that of nonresponders (stable disease/progressive disease) was 7.5 months. The one-year and two-year cumulative survival rates for responders and nonresponders were $87 \% / 69 \%$ and $40 \% / 11 \%$, respectively. Thus, there was a significant difference in the overall survival rate between responders and nonresponders $(P=0.019$, Figure 1).

\section{Factors associated with survival}

We investigated the predictors of survival in patients who underwent 5-FU + IFN therapy. Univariate analysis identified total bilirubin concentration $(P=0.005)$, CLIP score $(P=0.019)$, and response to therapy $(P=0.033)$ as factors associated with survival (Table 2). Among these factors, multivariate analysis identified the response to therapy $(P=0.037)$ as a significant and independent determinant of survival (Table 3 ).

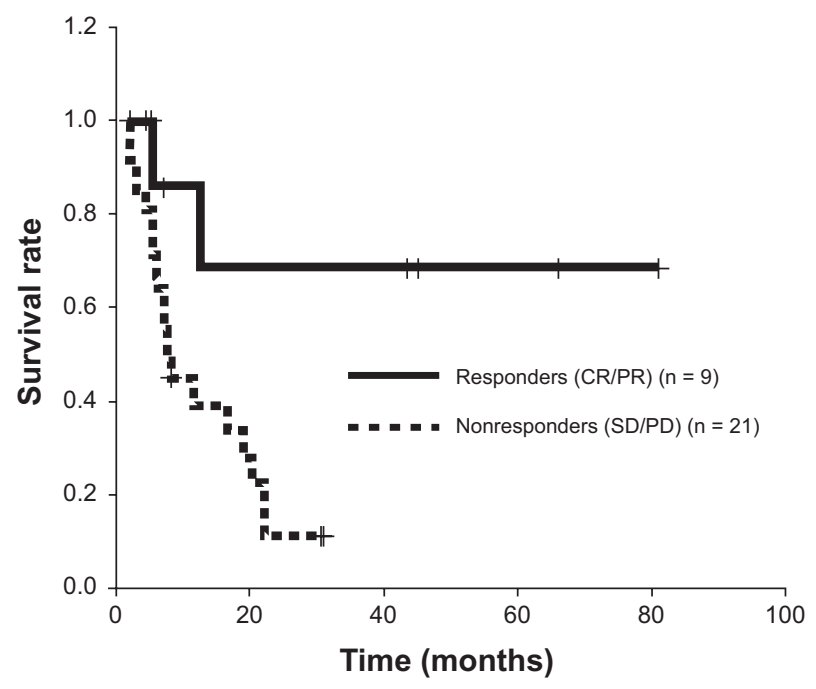

Figure I Comparison of overall survival rates of responders (complete response or partial response) and nonresponders (stable disease or progressive disease) to 5 -FU + IFN therapy. The survival rate was significantly higher in responders than in nonresponders (log-rank test, $P=0.019$ ).

Abbreviations: 5-FU, 5-fluorouracil; IFN, interferon.
Table 2 Univariate analysis of predictors for survival

\begin{tabular}{|c|c|c|c|}
\hline Variable & $\begin{array}{l}\text { Hazards } \\
\text { ratio }\end{array}$ & $95 \% \mathrm{Cl}$ & $P$ value \\
\hline Age & 0.956 & $0.907-1.007$ & 0.091 \\
\hline Male & 2.675 & $0.694-10.311$ & 0.153 \\
\hline $\mathrm{HBsAg}$ positive & 0.460 & $0.169-1.249$ & 0.128 \\
\hline Anti-HCV positive & 1.503 & $0.604-3.735$ & 0.381 \\
\hline Total bilirubin (mg/dL) & 3.222 & $1.420-7.313$ & 0.005 \\
\hline Albumin $(g / d L)$ & 0.413 & $0.143-1.193$ & 0.102 \\
\hline Prothrombin time (\%) & 0.964 & $0.917-1.014$ & 0.160 \\
\hline Platelet count $\left(\times 10^{4} / \mu \mathrm{L}\right)$ & 0.976 & $0.918-1.036$ & 0.976 \\
\hline $\operatorname{AFP}(<100 \mathrm{ng} / \mathrm{mL})$ & 1.372 & $0.55 I-3.416$ & 0.497 \\
\hline AFP-L3 (<20\%) & 1.509 & $0.6 \mid 0-3.731$ & 0.373 \\
\hline $\mathrm{DCP}(<100 \mathrm{mAU} / \mathrm{mL})$ & 0.445 & $0.101-1.954$ & 0.283 \\
\hline Child-Pugh status A & 2.549 & $0.950-6.843$ & 0.063 \\
\hline Tumor stage III & 2.995 & $0.858-10.460$ & 0.086 \\
\hline JIS score $(<3)$ & 2.995 & $0.858-10.460$ & 0.086 \\
\hline CLIP score $(<3)$ & 3.421 & $1.222-9.576$ & 0.019 \\
\hline $\begin{array}{l}\text { Portal vein invasion } \\
\left(<V_{p} 3\right)\end{array}$ & 2.288 & $0.87 I-6.010$ & 0.093 \\
\hline $\begin{array}{l}\text { Response to therapy } \\
\text { (CR or PR) }\end{array}$ & 4.960 & I.136-21.668 & 0.033 \\
\hline
\end{tabular}

Abbreviations: $\mathrm{Cl}$, confidence interval; $\mathrm{HBsAg}$, hepatitis $\mathrm{B}$ surface antigen; $\mathrm{HCV}$, hepatitis C virus; NBNC, non-HBV non-HCV; AFP, $\alpha$-fetoprotein; DCP, des- $\gamma$ carboxy prothrombin; TNM, tumor node metastasis; LCSG], Liver Cancer Study Group of Japan; JIS, Japan Integrated Staging; CLIP, Cancer of the Liver Italian Program; CR, complete response; PR, partial response.

\section{Factors associated with response to combination therapy}

We examined factors associated with the response to 5 -FU + IFN therapy, because response to therapy was found to be the only independent factor associated with survival in patients who underwent treatment with this combination. However, univariate and multivariate analyses did not identify any significant factors associated with response to the combination therapy (Table 4).

\section{IFNAR2 in peripheral blood mononuclear cells and response to 5-FU + IFN}

To explore factors associated with the response to the combination treatment, we next measured IFNAR2 mRNA expression in peripheral blood mononuclear cells in 11 patients from whom peripheral blood mononuclear cells were

Table 3 Multivariate analysis of predictors for survival

\begin{tabular}{llll}
\hline Variable & $\begin{array}{l}\text { Hazards } \\
\text { ratio }\end{array}$ & $\mathbf{9 5 \%} \mathbf{C l}$ & P value \\
\hline Total bilirubin $(\mathrm{mg} / \mathrm{dL})$ & $\mathrm{I} .076$ & $0.484-3.7 \mathrm{II}$ & 0.574 \\
CLIP score $(<3)$ & 3.434 & $0.907-13.000$ & 0.069 \\
Response to therapy & 5.478 & $\mathrm{I} .108-27.093$ & 0.037 \\
(CR or PR) & & & \\
\hline
\end{tabular}

Abbreviations: CLIP, Cancer of the Liver Italian Program; CR, complete response; $\mathrm{PR}$, partial response; $\mathrm{Cl}$, confidence interval. 
Table 4 Univariate and multivariate analyses of predictors for the response to 5-FU + IFN therapy

\begin{tabular}{|c|c|c|c|c|c|c|}
\hline \multirow[t]{2}{*}{ Variable } & \multicolumn{3}{|c|}{ Univariate analysis } & \multicolumn{3}{|c|}{ Multivariate analysis } \\
\hline & Odds ratio & $95 \% \mathrm{Cl}$ & $P$ value & Odds ratio & $95 \% \mathrm{Cl}$ & $P$ value \\
\hline Age & 1.034 & $0.95 \mathrm{I}-\mathrm{I} .125$ & 0.431 & - & - & - \\
\hline Male & 0.333 & $0.053-2.115$ & 0.244 & 0.266 & $0.036-1.966$ & 0.194 \\
\hline HBsAg positive & 0.250 & $0.026-2.416$ & 0.231 & 0.204 & $0.019-2.216$ & 0.191 \\
\hline Anti-HCV positive & 1.818 & $0.357-9.272$ & 0.472 & - & - & - \\
\hline Total bilirubin (mg/dL) & 0.607 & $0.132-2.796$ & 0.552 & - & - & - \\
\hline Albumin $(g / d L)$ & 1.139 & $0.206-6.297$ & 0.882 & - & - & - \\
\hline Prothrombin time (\%) & 0.976 & $0.912-1.045$ & 0.486 & - & - & - \\
\hline Platelet count $\left(\times 10^{4} / \mu \mathrm{L}\right)$ & 1.012 & $0.915-1.118$ & 0.820 & - & - & - \\
\hline $\operatorname{AFP}(<100 \mathrm{ng} / \mathrm{mL})$ & 0.880 & $0.183-4.226$ & 0.873 & - & - & - \\
\hline AFP-L3 $(<20 \%)$ & 0.727 & $0.151-3.493$ & 0.691 & - & - & - \\
\hline $\mathrm{DCP}(<100 \mathrm{AU} / \mathrm{mL})$ & 0.750 & $0.067-8.363$ & 0.815 & - & - & - \\
\hline Child-Pugh status A & 3.198 & $0.326-31.39$ & 0.318 & - & - & - \\
\hline Tumor stage III & 0.914 & $0.142-5.902$ & 0.925 & - & - & - \\
\hline JIS score $(<3)$ & 0.914 & $0.142-5.902$ & 0.925 & - & - & - \\
\hline CLIP score $(<3)$ & 2.031 & $0.417-9.886$ & 0.380 & - & - & - \\
\hline Portal vein invasion $\left(<V_{p} 3\right)$ & 2.031 & $0.417-9.886$ & 0.380 & - & - & - \\
\hline
\end{tabular}

Abbreviations: $\mathrm{HBsAg}$, hepatitis B surface antigen; HCV, hepatitis C virus; NBNC, non-HBV non-HCV; AFP, $\alpha$-fetoprotein; DCP, des- $\gamma$-carboxy prothrombin; TNM, tumor node metastasis; LCSGJ, Liver Cancer Study Group of Japan; JIS, Japan integrated staging; CLIP, Cancer of the Liver Italian Program.

available before therapy, because the effect of 5-FU + IFN has been demonstrated to depend significantly on hepatic IFNAR2 expression, ${ }^{17}$ and there is a significant correlation between IFNAR2 expression in the liver and peripheral blood mononuclear cells. ${ }^{26}$ Seven of the 11 patients were responders (complete response/partial response) and the remaining four patients were nonresponders (stable disease/ progressive disease). The expression level of IFNAR2 in peripheral blood mononuclear cells was significantly $(P=0.012)$ higher in responders $(6.5 \pm 2.4)$ than in nonresponders $(2.4 \pm 0.6$, see Figure 2$)$.

\section{Adverse reactions and complications}

Most patients complained of flu-like symptoms, including fever, nausea, and loss of appetite, but the degree of these adverse reactions was NCI-CTC Grade 1 or 2. Among patients with NCI-CTC Grade 3 adverse reactions, stomatitis was observed in two patients, diarrhea in one, leukopenia in one, thrombocytopenia in one, and hemorrhagic gastric ulcer in another. None of the patients required administration of granulocyte colony-stimulating factor or blood transfusion. There were five complications resulting from the arterial catheter, ie, occlusion in two patients, infection associated with the indwelling catheter in two patients, and dislocation in a further patient.

\section{Additional therapy}

Three patients each were treated with transcatheter arterial chemoembolization and intra-arterial 5-FU + cisplatin, respectively, after identification of progressive disease. Three patients assessed to exhibit a partial response had additional therapy, one of whom underwent partial hepatectomy because of downstaging of hepatocellular carcinoma, and the other two were repeatedly treated with transcatheter arterial chemoembolization because of dislocation of an indwelling intra-arterial catheter or downstaging of

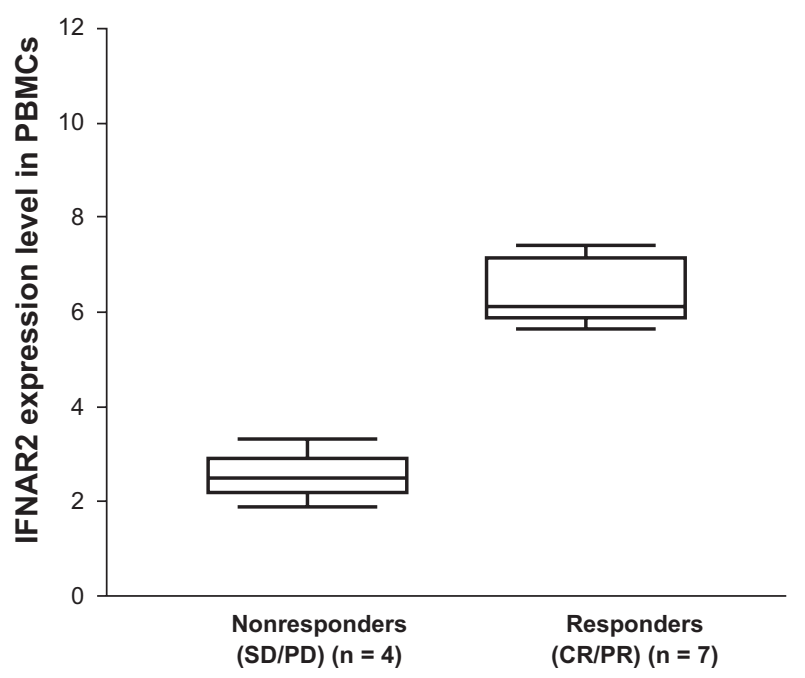

Figure 2 Expression levels of IFNAR2 in peripheral blood mononuclear cells in responders (complete response or partial response) and nonresponders (stable disease or progressive disease) to 5-FU + IFN therapy. The relative quantities of IFNAR2 mRNA in peripheral blood mononuclear cells were normalized to $\beta$-actin mRNA. The results are shown as box plot profiles. The bottom and top edges of the boxes are the 25 th and 75 th percentiles, respectively. Median values are shown by the lines within the boxes. IFNAR2 expression was significantly higher in responders than in nonresponders (Mann-Whitney $U$ test, $P=0.012$ ).

Abbreviations: IFNAR2, Type I interferon alpha receptor 2; 5-FU, 5-fluorouracil; IFN, interferon. 
hepatocellular carcinoma. Twenty-one patients, including the complete responder, did not have additional therapy.

\section{Discussion}

The response rate $(30 \%)$, median survival (7.5 months), and one-year and two-year cumulative survival rates $(53 \%$ and $33 \%$ ) for patients in this study were comparable with those reported for previous studies. ${ }^{17-19}$ Although the median survival time of nonresponders was identical to that of all patients ( 7.5 months), the mean survival time of nonresponders (343 \pm 272 days) was shorter than that for all patients ( $505 \pm 574$ days). This may be explained by the fact that some responders with advanced hepatocellular carcinoma showed considerably long survival, as shown in the Kaplan-Meier survival curve. One complete responder (2402 days) and one partial responder (1957 days) who underwent partial hepatectomy as additional therapy remain alive without recurrence of hepatocellular carcinoma. Two partial responders treated with transcatheter arterial chemoembolization as additional therapy showed long survival (1326 days and 1280 days). Thus, adequate additional therapy preceded by downstaging of hepatocellular carcinoma in response to the 5-FU + IFN combination may be important for responders to obtain long survival.

Several possible mechanisms for the anticancer effects of 5-FU + IFN therapy have been proposed. Transcription of the tumor suppressor p53 gene has been demonstrated to be induced by IFN- $\alpha / \beta$, accompanied by an increase in $\mathrm{p} 53$ protein levels, suggesting the integration of IFN- $\alpha / \beta$ signaling into p53 responses in tumor suppression. ${ }^{27}$ Yamamoto et al reported that the tumor necrosis factor-related apoptosisinducing ligand receptor-mediated cytotoxic pathway could be involved in the antihepatocellular carcinoma effect of the 5 -FU + IFN combination. ${ }^{28}$ It is also possible that IFN and 5 -FU reinforce the antitumor action of each other or have additive effects. The cytotoxic effect of 5-FU enhanced by IFN in various cultured malignant cells and upregulation of 5-FU activity when combined with IFN has been demonstrated. ${ }^{29-31}$

Response to therapy was the sole significant and independent predictor for survival of patients with advanced hepatocellular carcinoma who received the 5-FU + IFN combination in the present study. It should be noted that identification of response to therapy (complete response or partial response) as a predictor for survival was common to three Japanese studies, ${ }^{17-19}$ in addition to our study, despite different patient populations based on different grades of portal venous invasion and/or different evaluations of responses to therapy (RECIST or ECOG criteria). These results suggest that the response to therapy (complete response or partial response) is indeed critical for patients with advanced hepatocellular carcinoma who receive the 5-FU + IFN combination to have better survival.

Although previous studies have demonstrated several predictors of survival other than response to therapy, such as positivity for anti-HCV antibodies, performance status, and/or total bilirubin level, ${ }^{18,19}$ this discrepancy may be explained by the different patient populations in the relevant studies as a result of the different eligibility criteria used. In contrast, use of the same criteria for evaluation of response to therapy (RECIST), in addition to similar patient populations, showed almost the same objective response rates (complete response and partial response patients/all patients) in our study (30\%) and that of Uka et al (29\%). ${ }^{19}$ Despite the prominent improvement in survival of responders (complete response or partial response), it must be acknowledged that the response rates were not satisfactory, suggesting that more than half of patients with advanced hepatocellular carcinoma would remain unresponsive to the $5-\mathrm{FU}+\mathrm{IFN}$ combination. We also have to consider that this combination therapy has a considerable negative impact on quality of life for patients with advanced hepatocellular carcinoma, even though adverse reactions were rarely severe in the present study. Therefore, it appears to be very important to predict responders beforehand in the clinical setting.

Ota et al demonstrated that, among several clinical parameters, including $\alpha$-fetoprotein, des- $\gamma$-carboxy prothrombin, Child-Pugh score, and CLIP score, the hepatic expression of IFNAR2 was the only significant predictor of clinical response to 5 -FU + IFN therapy. ${ }^{17}$ It is particularly noteworthy that all patients without IFNAR2 expression in hepatocellular carcinoma tissue are not responsive to 5-FU + IFN therapy. The importance of IFNAR2 expression for the anticancer effect of 5-FU + IFN has also been shown by in vitro analysis. ${ }^{32,33}$ IFNAR2 expression in hepatocellular carcinoma tissue was assessed immunohistochemically at the protein level in the study by Ota et al. We have previously shown a correlation between IFNAR2 protein expression and IFNAR2 mRNA expression in liver specimens from patients with chronic hepatitis C. ${ }^{34}$ We have also found a correlation between IFNAR2 mRNA expression in peripheral blood mononuclear cells and in the livers of patients with chronic hepatitis C. ${ }^{26}$ Therefore, IFNAR2 expression in hepatocellular carcinoma tissue is likely to be correlated with that in 
peripheral blood mononuclear cells, even though there have been no reports explaining the possible mechanisms for this correlation, as far as we know. Liver biopsy is sometimes difficult to perform before combination therapy in patients with advanced hepatocellular carcinoma because of the bleeding tendency arising from a low count platelet and/or decreased activity of prothrombin. IFNAR2 mRNA expression in peripheral blood mononuclear cells was significantly higher in responders (complete response or partial response) than in nonresponders (stable disease or progressive disease) in the present study. Based on these results, we propose a testable hypothesis that IFNAR2 expression in peripheral blood mononuclear cells may be a practical predictor of response to the 5-FU + IFN combination.

Several limitations existed in this study. First, a significant percentage of patients who fulfilled the eligibility criteria could not be included due to lack of written informed consent. Second, the number of patients in whom IFNAR2 expression was examined for peripheral blood mononuclear cells was too small to draw a definitive conclusion. We could not evaluate if IFNAR2 expression in peripheral blood mononuclear cells could be an independent predictor for response to the 5 -FU + IFN combination in multivariate analysis. Further studies need to be conducted in a larger number of patients to clarify the clinical usefulness of measurement of IFNAR2 expression in peripheral blood mononuclear cells as a predictor of response to the 5-FU + IFN combination. Third, the correlation between IFNAR2 protein expression and IFNAR2 mRNA expression in peripheral blood mononuclear cells was not examined, even though we have previously confirmed this correlation in the liver.

In conclusion, we have shown preliminary evidence that IFNAR2 expression in peripheral blood mononuclear cells may predict the response to 5-FU + IFN therapy beforehand in patients with advanced hepatocellular carcinoma, which should enable us to treat those patients who are likely to respond to this combination therapy in a selective manner.

\section{Acknowledgments}

We thank Dr K Okita of Shimonoseki Kohsei Hospital for helpful discussion and critical advice. This study was supported by a grant from the Ministry of Education, Culture, Sports, Science and Technology, and in part by the Ministry of Health, Labor and Welfare, Japan.

\section{Disclosure}

The authors report no conflicts of interest in this work.

\section{References}

1. Parkin DM, Bray F, Ferlay J, Pisani P. Global cancer statistics, 2002. CA Cancer J Clin. 2005;55:74-108.

2. Okuda K, Fujimoto I, Hanai A, Urano Y. Changing incidence of hepatocellular carcinoma in Japan. Cancer Res. 1987;47:4967-4972.

3. El-Serag HB, Mason AC. Rising incidence of hepatocellular carcinoma in the United States. N Engl J Med. 1999;340:745-750.

4. Shinagawa T, Ohto M, Kimura K, et al. Diagnosis and clinical features of small hepatocellular carcinoma with emphasis on the utility of realtime ultrasonography. A study in 51 patients. Gastroenterology. 1984; 86:495-502.

5. Yoshida H, Itai Y, Ohtomo K, Kokubo T, Minami M, Yashiro N. Small hepatocellular carcinoma and cavernous hemangioma: Differentiation with dynamic FLASH MR imaging with Gd-DTPA. Radiology. 1989; 171:339-342.

6. Matsui O, Takashima T, Kadoya M, et al. Dynamic computed tomography during arterial portography: The most sensitive examination for small hepatocellular carcinomas. J Comput Assist Tomogr. 1985;9: 19-24.

7. Ichikawa T, Saito K, Yoshioka N, et al. Detection and characterization of focal liver lesions: A Japanese phase III, multicenter comparison between gadoxetic acid disodium-enhanced magnetic resonance imaging and contrast-enhanced computed tomography predominantly in patients with hepatocellular carcinoma and chronic liver disease. Invest Radiol. 2010;45:133-141.

8. Makuuchi M, Kosuge T, Takayama T, et al. Surgery for small liver cancers. Semin Surg Oncol. 1993;9:298-304.

9. Mazzaferro V, Regalia E, Doci R, et al. Liver transplantation for the treatment of small hepatocellular carcinomas in patients with cirrhosis N Engl J Med. 1996;334:693-699.

10. Shiina S, Teratani T, Obi S, et al. A randomized controlled trial of radiofrequency ablation with ethanol injection for small hepatocellular carcinoma. Gastroenterology. 2005;129:122-130.

11. Llovet JM, Real MI, Montaña X, et al. Arterial embolisation or chemoembolisation versus symptomatic treatment in patients with unresectable hepatocellular carcinoma: A randomised controlled trial. Lancet. 2002;359:1734-1739.

12. Llovet JM, Bustamante J, Castells A, et al. Natural history of untreated nonsurgical hepatocellular carcinoma: Rationale for the design and evaluation of therapeutic trials. Hepatology. 1999;29:62-67.

13. Cancer of the Liver Italian Program (CLIP) investigators. A new prognostic system for hepatocellular carcinoma: A retrospective study of 435 patients: The Cancer of the Liver Italian Program (CLIP) investigators. Hepatology. 1998;28:751-755.

14. Llovet JM, Ricci S, Mazzaferro V, et al. Sorafenib in advanced hepatocellular carcinoma. N Engl J Med. 2008;359:378-390.

15. Kudo M, Okanoue T. Management of hepatocellular carcinoma in Japan: Consensus-based clinical practice manual proposed by the Japan Society of Hepatology. Oncology. 2007;72:S2-S15.

16. Sakon M, Nagano H, Dono K, et al. Combined intraarterial 5-fluorouracil and subcutaneous interferon-alpha therapy for advanced hepatocellular carcinoma with tumor thrombi in the major portal branches. Cancer. 2002;94:435-442.

17. Ota H, Nagano H, Sakon M, et al. Treatment of hepatocellular carcinoma with major portal vein thrombosis by combined therapy with subcutaneous interferon-alpha and intra-arterial 5-fluorouracil; role of type 1 interferon receptor expression. Br J Cancer. 2005;93:557-564.

18. Obi S, Yoshida H, Toune R, et al. Combination therapy of intraarterial 5 -fluorouracil and systemic interferon-alpha for advanced hepatocellular carcinoma with portal venous invasion. Cancer. 2006;106: 1990-1997.

19. Uka K, Aikata H, Takaki S, et al. Pretreatment predictor of response, time to progression, and survival to intraarterial 5-fluorouracil/interferon combination therapy in patients with advanced hepatocellular carcinoma. J Gastroenterol. 2007;42:845-853. 
20. Ando E, Yamashita F, Tanaka M, Tanikawa K. A novel chemotherapy for advanced hepatocellular carcinoma with tumor thrombosis of the main trunk of the portal vein. Cancer. 1997;79:1890-1896.

21. Ando E, Tanaka M, Yamashita F, et al. Hepatic arterial infusion chemotherapy for advanced hepatocellular carcinoma with portal vein tumor thrombosis: Analysis of 48 cases. Cancer. 2002;95:588-595.

22. Oken MM, Creech RH, Tormey DC, et al. Toxicity and response criteria of the Eastern Cooperative Oncology Group. Am J Clin Oncol. 1982; 5:649-655.

23. Therasse P, Arbuck SG, Eisenhauer EA, et al. New guidelines to evaluate the response to treatment in solid tumors. European Organization for Research and Treatment of Cancer, National Cancer Institute of the United States, National Cancer Institute of Canada. J Natl Cancer Inst. 2000;92:205-216.

24. Kamai T, Yanai Y, Arai K, et al. Increased interferon alpha receptor 2 mRNA levels is associated with renal cell carcinoma metastasis. $B M C$ Cancer. 2007; 7:159.

25. Kudo M, Chung H, Haji S, et al. Validation of a new prognostic staging system for hepatocellular carcinoma: The JIS score compared with the CLIP score. Hepatology. 2004;40:1396-1405.

26. Yamaguchi Y, Hino K, Fujiwara D, et al. Expression of type I interferon receptor in liver and peripheral blood mononuclear cells in chronic hepatitis C patients. Dig Dis Sci. 2002;47:1611-1617.

27. Takaoka A, Hayakawa S, Yanai H, et al. Integration of interferon-alpha/ beta signalling to p53 responses in tumour suppression and antiviral defence. Nature. 2003;424:516-523.
28. Yamamoto T, Nagano H, Sakon M, et al. Partial contribution of tumor necrosis factor-related apoptosis-inducing ligand (TRAIL)/TRAIL receptor pathway to antitumor effects of interferon-alpha/5-fluorouracil against Hepatocellular Carcinoma. Clin Cancer Res. 2004;10:7884-7895.

29. Wadler S, Schwartz EL. Antineoplastic activity of the combination of interferon and cytotoxic agents against experimental and human malignancies: A review. Cancer Res. 1990;50:3473-3486.

30. Schwartz EL, Hoffman M, O'Connor CJ, Wadler S. Stimulation of 5-fluorouracil metabolic activation by interferon-alpha in human colon carcinoma cells. Biochem Biophys Res Commun. 1992;182:1232-1239.

31. Damdinsuren B, Nagano H, Sakon M, et al. Interferon-beta is more potent than interferon-alpha in inhibition of human hepatocellular carcinoma cell growth when used alone and in combination with anticancer drugs. Ann Surg Oncol. 2003;10:1184-1190.

32. Yano H, Iemura A, Haramaki M, et al. Interferon alfa receptor expression and growth inhibition by interferon alfa in human liver cancer cell lines. Hepatology. 1999;29:1708-1717.

33. Eguchi H, Nagano H, Yamamoto H, et al. Augmentation of antitumor activity of 5-fluorouracil by interferon alpha is associated with upregulation of p27 Kip1 in human hepatocellular carcinoma cells. Clin Cancer Res. 2000;6:2881-2890.

34. Fujiwara D, Hino K, Yamaguchi Y, et al. Hepatic expression of type I interferon receptor for predicting response to interferon therapy in chronic hepatitis C patients: A comparison of immunohistochemical method vs competitive polymerase chain reaction assay. Hepatol Res. $2003 ; 25: 377-384$.
Hepatic Medicine: Evidence and Research

\section{Publish your work in this journal}

Hepatic Medicine: Evidence and Research is an international, peerreviewed, open access journal covering all aspects of adult and pediatric hepatology in the clinic and laboratory including the following topics: Pathology, pathophysiology of hepatic disease; Investigation and treatment of hepatic disease; Pharmacology of drugs used for

\section{Dovepress}

the treatment of hepatic disease. Issues of patient safety and quality of care will also be considered. The manuscript management system is completely online and includes a very quick and fair peer-review system, which is all easy to use. Visit http://www.dovepress.com/ testimonials.php to read real quotes from published authors. 